\title{
PENENTUAN CADANGAN PREMI DENGAN PERHITUNGAN PROSPEKTIF UNTUK ASURANSI PENDIDIKAN
}

\author{
Anggie Ezra Julianda Hutapea ${ }^{1 \S}$, I Nyoman Widana ${ }^{2}$, Luh Putu Ida Harini ${ }^{3}$ \\ ${ }^{1}$ Program Studi Matematika, Fakultas MIPA - UniversitasUdayana [Email: anggie.hutapea02@gmail.com] \\ ${ }^{2}$ Program Studi Matematika, Fakultas MIPA - UniversitasUdayana [Email:nwidana@yahoo.com] \\ ${ }^{3}$ Program Studi Matematika, Fakultas MIPA - UniversitasUdayana [Email: ballidah@ gmail.com] \\ ${ }^{\S}$ Corresponding Author
}

\begin{abstract}
The purpose of this research is to get formula to calculate premium reserve value with prospective calculation for education insurance. This study examines the value of premium reserves for people aged 40 years with a coverage period of 17 years. In determining the value of premium reserve using the prospective calculation. It will be started by completing the value of the Indonesian Mortality Table 2011 using the interest rate of 6.5\%, calculating the cash value of the benefit, the annuity value, the net annual premium value, and the net monthly premium value. The results of this study indicate that the value of premium reserves with a prospective calculation for benefits paid at the end of the year and the premium reserve value for benefits paid at the time the insured dies, its value with the value of the cash price set by the insurer at the end of year- 17 on the insurance contract.
\end{abstract}

Keywords: Education insurance, the premium reserve, a prospective.

\section{PENDAHULUAN}

Risiko adalah hal yang tidak bisa dihindari dalam kehidupan sehari-hari. Untuk meminimalkan suatu risiko, ditawarkan berbagai macam produk asuransi. Asuransi adalah persetujuan dimana pihak yang menjamin berjanji kepada pihak yang dijamin untuk menerima sejumlah uang premi sebagai pengganti kerugian, yang mungkin akan diderita oleh yang dijamin akibat suatu peristiwa yang belum jelas (Prodjodikoro, 1987). Berbagai produk asuransi yang ditawarkan oleh perusahaan yaitu asuransi kesehatan, asuransi kecelakaan, dan asuransi pendidikan. Asuransi pendidikan adalah jenis asuransi yang memberikan jaminan biaya pendidikan kepada pihak tertanggung dengan sebagian premi yang telah dibayarkan oleh pihak tertanggung.

Pada kenyataannya, perusahaan dalam mengelola suatu produk asuransi tidak selalu mengalami keuntungan. Bahkan tidak sedikit perusahaan asuransi yang mengalami kerugian yang disebabkan karena perusahaan tidak tepat dalam mengatur cadangan premi. Akibatnya, perusahaan asuransi tidak mampu membayar uang pertanggungan kepada pihak tertanggung ketika jumlah klaim yang diajukan pihak tertanggung ternyata melebihi jumlah klaim yang diprediksi sebelumnya. Masalah tersebut dapat diantisipasi dengan menentukan cadangan premi dengan tepat (Destriani et al, 2014).

Metode perhitungan cadangan premi bersih ada dua yaitu perhitungan secara retrospektif dan perhitungan prospektif. Perhitungan secara retrosektif merupakan perhitungan cadangan premi berdasarkan jumlah total pendapatan diwaktu lampau. Sedangkan, perhitungan secara prospektif merupakan perhitungan cadangan premi berdasarkan nilai sekarang dari semua pendapatan diwaktu yang akan datang. Kedua metode ini menghasilkan hasil cadangan yang sama (Futami, 1993).

Penelitian ini bertujuan untuk mendapatkan formula cadangan premi untuk asuransi pendidikan dengan perhitungan prospektif dan menentukan besar cadangan premi untuk asuransi pendidikan dengan perhitungan 
prospektif.

Selanjutnya dibahas komponen-komponen yang diperlukan dalam penentuan cadangan premi untuk asuransi pendidikan menggunakan metode perhitungan prospektif, yaitu:

Tingkat suku bunga adalah persentase pembayaran modal yang dipinjam dari lain pihak (Sukirno, 1994). Cara perhitungan tingkat suku bunga yang digunakan yaitu tingkat suku bunga majemuk (Futami, 1993):

$$
v=\frac{1}{(1+i)}
$$

Nilai tunai manfaat adalah sejumlah uang pertanggungan diterima pihak tertanggung pada saat melakukan klaim. Nilai tunai dari manfaat untuk tiap satu unit pembayaran pada akhir tahun kematian [Futami, 1993]. Dirumuskan dengan persamaan:

$$
A_{x: n}^{1}=\frac{M_{x}-M_{x+n}+D_{x+n}}{D_{x}}
$$

Suatu anuitas yang pembayaran preminya dikaitkan pada kematian seseorang disebut anuitas hidup (Futami, 1993). Untuk menghitung Actuarial Present Value (nilai sekarang) dari anuitas hidup didefinisikan (Dickson, 2009):

$$
\begin{aligned}
\ddot{a}_{x: \bar{n} \mid} & =\sum_{k=0}^{n-1} v^{k} \cdot{ }_{k} p_{x} \\
& =\frac{N_{x}-N_{x+n}}{D_{x}}
\end{aligned}
$$

Suatu anuitas awal dalam satu tahun dilakukan sebanyak $k$ kali pembayaran dan besarnya tiap kali pembayaran adalah $\frac{1}{k}$ dengan pembayaran $n$ tahun disebut anuitas hidup berjangka (Sembiring, 1986). Dirumuskan sebagai berikut:

$$
\ddot{a}_{x: \bar{n} \mid}^{(k)}=\ddot{a}_{x: \bar{n} \mid}-\frac{k-1}{2 k}\left(1-v^{n}{ }_{n} p_{x}\right)
$$

Premi adalah sejumlah uang yang harus dibayarkan sebagai suatu kewajiban dari pihak tertanggung. Untuk menghitung premi tahunan digunakan persamaan (Dickson, 2009):

$$
P=\frac{A_{x: \bar{n} \mid}}{\ddot{a}_{x: \bar{n} \mid}}
$$

Premi bulanan adalah premi yang dibayarkan 12 kali dalam satu tahun (Futami, 1993). Premi bulanan dapat ditentukan dengan menggunakan prinsip ekuivalensi:

$$
\text { 12. } P^{(12)} \cdot \ddot{a}_{x: \bar{n} \mid}^{(12)}=A_{x: \bar{n} \mid}
$$

Menurut (Dickson, 2009), cadangan adalah ekspektasi nilai sekarang dari variabel acak kerugian bersih yang akan terjadi dimasa yang akan datang. Persamaannya sebagai berikut:

$$
\begin{aligned}
{ }_{t} V_{x}= & \frac{1}{l_{x+t}}\left(v \cdot d_{x+t}+v^{2} \cdot d_{x+t+1}+\cdots\right. \\
& \left.+v^{n-t} \cdot d_{x+n-1}\right)-P\left(l_{x+t}+v \cdot l_{x+t+1}+\cdots\right. \\
& \left.+v^{n-t-1} \cdot l_{x+n-1}\right)
\end{aligned}
$$

\section{METODE PENELITIAN}

Penelitian ini menggunakan data sekunder, yaitu data yang diperoleh dari salah satu perusahaan asuransi. Pengolahan data pada penelitian ini dibantu dengan menggunakan Software Microsoft Exel. Langkah-langkah yang dilakukan pada penelitian ini adalah sebagai berikut:

a. Melengkapi nilai tabel mortalitas berdasarkan Tabel Mortalitas Indonesia 2011.

b. Membuat tabel komutasi yang berisi nilai $v$ dan fungsi-fungsi komutasi.

c. Menentukan formula untuk penentuan cadangan premi asuransi pendidikan.

d. Melakukan perhitungan premi asuransi pendidikan untuk pihak tertanggung yang berusia $x$ tahun dengan benefit yang dibayarkan pada akhir tahun dengan langkahlangkah: (a) menghitung nilai tunai manfaat; (b) menghitung nilai anuitas hidup berjangka; (c) menghitung anuitas hidup berjangka dengan pembayaran dilakukan 12 kali dalam setahun; (d) menghitung premi tahunan bersih; (e) menghitung premi bulanan bersih; (f) menentukan formula untuk penentuan besar cadangan premi.

e. Menentukan besar cadangan premi asuransi pendidikan untuk benefit yang dibayarkan pada akhir tahun dengan perhitungan prospektif. 
f. Melakukan perhitungan premi asuransi pendidikan untuk pihak tertanggung yang berusia $x$ tahun dengan benefit yang dibayarkan pada pihak tertanggung meninggal dunia dengan langkah-langkah: (a) menghitung nilai tunai manfaat; (b) menghitung nilai anuitas hidup berjangka; (c) menghitung anuitas hidup berjangka dengan pembayaran 12 kali dalam setahun; (d) menghitung premi tahunan bersih; (e) menghitung premi bulanan bersih; (f) menentukan formula untuk penentuan cadangan premi.

g. Menentukan besar cadangan premi asuransi pendidikan untuk benefit yang dibayarkan pada saat pihak tertanggung meninggal dunia dengan perhitungan prospektif.

\section{I. HASIL DAN PEMBAHASAN}

Dalam melengkapi nilai tabel mortalitas diawali dengan menghitung nilai $d_{x}$ menggunakan persamaan yang dapat ditulis sebagai berikut:

$$
d_{x}=l_{x}-l_{x+1}
$$

Langkah selanjutnya adalah membuat tabel komutasi. Pada pembuatan tabel komutasi dilakukan perhitungan nilai $v$ dan nilai fungsifungsi komutasi yaitu $D_{x}, N_{x}, C_{x}, M_{x}, \bar{C}_{x}$ dan $\bar{M}_{x}$ dengan menggunakan suku bunga konstan yaitu $i=6,5 \%$. Perhitungannya adalah:

1. Perhitungan nilai $v$ adalah:

$$
v=\frac{1}{1+i}
$$

2. Perhitungan nilai $D_{x}$ adalah:

$$
D_{x}=v^{x} \cdot l_{x}
$$

3. Perhitungan nilai $N_{x}$ adalah:

$$
N_{x}=D_{x}+D_{x+1}+D_{x+2}+\cdots+D_{\omega-1}
$$

4. Perhitungan nilai $C_{x}$ adalah:

$$
C_{x}=v^{x+1} d_{x}
$$

5. Perhitungan nilai $M_{x}$ adalah:

$$
M_{x}=C_{x}+C_{x+1}+C_{x+2}+\cdots+C_{\omega-1}
$$

6. Perhitungan nilai $\bar{C}_{x}$ adalah:

$$
\bar{C}_{x}=v^{x+\frac{1}{2}} \cdot d_{x}
$$

7. Perhitungan nilai $\bar{M}_{x}$ adalah:

$$
\bar{M}_{x}=\bar{C}_{x}+\bar{C}_{x+1}+\bar{C}_{x+2}+\cdots+\bar{C}_{\omega-1}
$$

Selanjutnya, menentukan formula dengan perhitungan prospektif untuk menentukan besar nilai cadangan premi. Adapun rincian kontrak dalam program asuransi yang digunakan dalam penelitian ini adalah sebagai berikut: pihak tertanggung berusia $x$ tahun dengan jangka waktu pertanggungan selama $n$ tahun. Pihak tertanggung akan menerima sejumlah uang pertanggungan sebesar Rp.5.000.000 pada saat pihak tertanggung meninggal sebelum akhir kontrak dan tetap hidup pada akhir kontrak. Pihak tertanggung juga mendapatkan dana kelangsungan belajar sebesar Rp.500.000 pada tanggal 1 Juli 2008, Rp.1.000.000 pada tanggal 1 Juli 2014, Rp.1.500.000 pada tanggal 1 Juli 2017 dan Rp.2.000.000 yang akan dibayarkan sekaligus pada akhir kontrak yaitu 1 Juli 2020. Dana kelangsungan belajar dinotasikan dengan $A P_{t}$. Berdasarkan kontrak tersebut, maka pada persamaan (7) dimodifikasi sehingga diperoleh formula untuk penentuan besar nilai cadangan premi dengan benefit yang dibayarkan pada akhir tahun yaitu:

$$
\begin{aligned}
{ }_{t} V_{x}= & \frac{1}{l_{x+t}}\left[5 \cdot 1 0 ^ { 6 } \left(v \cdot d_{x+t}+v^{2} d_{x+t+1}+\cdots\right.\right. \\
& \left.\left.+v^{n-t} \cdot d_{x+n-1}+v^{n-t} \cdot l_{x+n}\right)\right]-P\left(l_{x+t}\right. \\
& \left.+v \cdot l_{x+t+1}+\cdots+v^{n-t-1} \cdot l_{x+n-1}\right) \\
& +A P_{t}
\end{aligned}
$$

Kemudian dipermudah kedalam bentuk fungsi komutasi yaitu:

Kemungkinan peluang orang meninggal yang dinotasikan dengan:

$$
\left(v \cdot d_{x+t}+v^{2} \cdot d_{x+t+1}+\cdots+v^{n-t} \cdot d_{x+n-1}\right)
$$

Dimisalkan dengan $A$, sehingga diperoleh:

$$
\begin{aligned}
A & =\frac{v \cdot d_{x+t}+v^{2} \cdot d_{x+t+1}+\cdots+v^{n-t} \cdot d_{x+n-1}}{l_{x+t}} \\
& =\frac{v \cdot d_{x+t}+v^{2} \cdot d_{x+t+1}+\cdots+v^{n+x-x-t} \cdot d_{x+t-t+n-1}}{l_{x+t}} \\
& =\left(\frac{v \cdot d_{x+t}+v^{2} \cdot d_{x+t+1}+\cdots+v^{n+x-x-t} \cdot d_{x+t-t+n-1}}{l_{x+t}}\right) \cdot \frac{v^{x+t}}{v^{x+t}} \\
& =\left(\frac{v^{x+t+1} \cdot d_{x+t}+v^{x+t+2} \cdot d_{x+t+1}+\cdots+v^{x+n} \cdot d_{x+n-1}}{D_{x+t}}\right) \\
& =\frac{C_{x+t}+C_{x+t+1}+\cdots+C_{x+n-1}}{D_{x+t}} \\
& =\frac{M_{x+t}-M_{x+n}}{D_{x+t}}
\end{aligned}
$$

Kemungkinan peluang orang akan tetap hidup yang dinotasika dengan:

$$
\left(l_{x+t}+v \cdot l_{x+t+1}+\cdots+v^{n-t-1} \cdot l_{x+n-1}\right)
$$

Dimisalkan dengan $B$, sehingga diperoleh: 


$$
\begin{aligned}
B & =\frac{l_{x+t}+v \cdot l_{x+t+1}+\cdots+v^{n-t-1} \cdot l_{x+n-1}}{l_{x+t}} \\
& =\frac{l_{x+t}+v \cdot l_{x+t+1}+\cdots+v^{n-t-1} \cdot l_{x+t-t+n-1}}{l_{x+t}} \\
& =\left(\frac{l_{x+t}+v \cdot l_{x+t+1}+\cdots+v^{n-t-1} \cdot l_{x+t-t+n-1}}{l_{x+t}}\right) \cdot \frac{v^{x+t}}{v^{x+t}} \\
& =\frac{\left(D_{x+t}\right)+\left(D_{x+t+1}\right)+\left(D_{x+t+2}\right)+\cdots+\left(D_{x+t+n-t-1}\right)}{D_{x+t}} \\
& =\frac{N_{x+t}-N_{x+n}}{D_{x+t}}
\end{aligned}
$$

Sehingga diperoleh formula cadangan premi yang benefitnya dibayarkan pada akhir tahun dalam bentuk fungsi komutasi yaitu:

$$
\begin{aligned}
{ }_{t} V_{x}= & \frac{1}{l_{x+t}}\left[5.10^{6}\left(\frac{M_{x+t}-M_{x+n}}{D_{x+t}}\right)+l_{x+n} \cdot v^{n-t}\right] \\
& -P\left(\frac{N_{x+t}-N_{x+n}}{D_{x+t}}\right)+A P_{t}
\end{aligned}
$$

Untuk formula untuk cadangan premi yang benefitnya dibayarkan pada saat pihak tertanggung meninggal dunia yaitu:

$$
\begin{aligned}
{ }_{t} \bar{V}_{x}= & \frac{1}{l_{x+t}}\left[5.10^{6}(1+i)^{\frac{1}{2}}\left(\frac{M_{x+t}+M_{x+n}}{D_{x+t}}\right)\right. \\
& +5.10^{6} \times l_{x+n} \cdot v^{n-t} \\
& -P\left(\frac{N_{x+t}+N_{x+n}}{D_{x+t}}\right)+A P_{t}
\end{aligned}
$$

Dari persamaan (2) akan dihitung nilai tunai manfaat untuk pihak tertanggung yang berusia 40 tahun dan jangka waktu pertanggungan 17 tahun dengan benefit yang dibayarkan pada akhir tahun, diperoleh:

$$
\begin{aligned}
A_{40: 17}^{p} & =\frac{M_{40}-M_{40+17}+D_{40+17}}{D_{40}} \\
& =\frac{1.072,06-758,36+2.459,11}{7.800,492} \\
& =0,355466077
\end{aligned}
$$

Kemudian hari persamaan (3) dihitung nilai anuitas hidup berjangka yang akan digunakan untuk benefit yang dibayarkan pada akhir tahun dan benefit yang dibayarkan pada saat pihak tertanggung meninggal dunia, diperoleh:

$$
\begin{aligned}
\ddot{a}_{40: \overline{17 \mid}} & =\frac{N_{40}-N_{40: 17}}{D_{40}} \\
& =\frac{82.376,63-27.860,33}{7.800,49} \\
& =10,56044043
\end{aligned}
$$

Dari persamaan (4) akan dihitung nilai anuitas hidup berjangka (pembayaran 12 kali dalam setahun) untuk benefit yang dibayarkan pada akhir tahun dan pada saat pihak tertanggung meninggal dunia, diperoleh:

$$
\begin{aligned}
\ddot{a}_{40: \overline{17 \mid}}^{(12)} & =\ddot{a}_{40: 17 \mid}-\frac{12-1}{2(12)}\left(1-v_{17}^{17} p_{40}\right) \\
& =10,56044-\left(\frac{11}{24}\right)(1-(0,3428)(0,9196)) \\
& =10,24659712
\end{aligned}
$$

Sebelum menghitung premi tahunan bersih dengan benefit yang dibayarkan pada akhir tahun, terlebih dahulu dilakukan perhitungan nilai tunai manfaat dana kelangsungan belajar untuk pihak tertanggung yang berusia 40 tahun dan jangka waktu 17 tahun. Uang pertanggungan yang didapat sebesar Rp.5.000.000 dan pihak tertanggung juga akan mendapat dana kelangsungan belajar sebesar Rp.500.000 pada tanggal 1 Juli 2008, Rp.1.000.000 pada tanggal 1 Juli 2014, Rp.1.500.000 pada tanggal 1 Juli 2017 dan Rp.2.000.000 pada tanggal 1 Juli 2020 yang dibayarkan sekaligus dengan uang pertanggungan, sehingga diperoleh:

$$
\begin{aligned}
A_{40: 17}^{p}= & 5.10^{6}\left(\frac{M_{40}-M_{57}+D_{57}}{D_{40}}\right)+5 \times 10^{6} \cdot v^{5} \\
& +1 \times 10^{6} \cdot v^{11}+1,5 \times 10^{5} \cdot v^{14} \\
& +2 \times 10^{6} \cdot v^{17} \\
& =3.949 .258,44
\end{aligned}
$$

Selanjutnya, dilakukan perhitungan untuk premi tahunan bersih asuransi pendidikan dengan benefit yang dibayarkan pada akhir tahun menggunakan persamaan (5):

$$
\begin{aligned}
P & =\frac{A_{40: 17}^{p}}{\ddot{a}_{40: \overline{17 \mid}}} \\
& =\frac{3.949 .258,44}{10,56044043} \\
& =373.967,21
\end{aligned}
$$

Menggunakan persamaan (6), nilai premi bulanan bersih asuransi pendidikan untuk benefit yang dibayarkan pada akhir tahun untuk pihak tertanggung yang berusia 40 tahun dengan jangka waktu pertanggungan selama 17 tahun adalah: 


$$
\begin{aligned}
P^{(12)} \cdot \ddot{a}_{40: 17 \mid}^{(12)} & =A_{40: 17}^{1 p} \\
P^{(12)} & =\frac{3.949 .258,44}{(12)(10,24659712)} \\
& =32.118,45
\end{aligned}
$$

Sebelum menentukan besar nilai cadangan premi, terlebih dahulu dihitung dana kelangsungan belajar untuk mendapatkan baris pertama $A P_{1}$, didapatkan dengan menggunakan persamaan:

$$
\begin{aligned}
A P_{1}= & 5.10^{5} \times v^{4}+1 \cdot 10^{6} \times v^{10} \\
& +1,5 \cdot 10^{6} \times v^{13}+2.10^{6} \times v^{16} \\
A P_{1}= & 5.10^{5} \times 0,77+1 \cdot 10^{6} \times 0,53 \\
& +1,5 \cdot 10^{6} \times 0,44+2.10^{6} \times 0,36 \\
= & 2.313 \cdot 103,38
\end{aligned}
$$

Berlaku juga untuk seterusnya. Hasil selengkapnya dapat dilihat pada tabel 1 .

Tabel 1. Nilai Dana Kelangsungan Belajar

\begin{tabular}{|c|c|}
\hline $\begin{array}{c}\text { Akhir Tahun } \\
\text { Ke- }(\mathrm{t})\end{array}$ & $A P_{t}$ \\
\hline 1 & $2.313 .103,38$ \\
\hline 2 & $2.463 .455,10$ \\
\hline 3 & $2.623 .579,68$ \\
\hline 4 & $2.794 .112,36$ \\
\hline 5 & $2.975 .729,66$ \\
\hline 6 & $2.636 .652,09$ \\
\hline 7 & $2.808 .034,48$ \\
\hline 8 & $2.990 .556,72$ \\
\hline 9 & $3.184 .942,91$ \\
\hline 10 & $3.391 .964,20$ \\
\hline 11 & $3.612 .441,87$ \\
\hline 12 & $2.782 .250,59$ \\
\hline 13 & $2.963 .096,88$ \\
\hline 14 & $3.155 .698,18$ \\
\hline 15 & $1.763 .318,56$ \\
\hline 16 & $1.877 .934,27$ \\
\hline 17 & 2.000 .000 \\
\hline
\end{tabular}

Setelah diperoleh nilai dana kelangsungan belajar $\left(A P_{t}\right)$ maka akan ditentukan besar nilai cadangan premi untuk benefit yang dibayarkan pada akhir tahun dengan menggunakan persamaan (17):

Cadangan Premi Tahun Ke-1:

${ }_{1} V_{40}=\frac{\left[5.10^{6}\left(\frac{M_{41}-M_{57}}{D_{41}}\right)+l_{57} \cdot v^{16}\right]-P\left(\frac{N_{41}-N_{57}}{D_{41}}\right)}{l_{41}}+A P_{1}$

berlaku juga untuk seterusnya. Hasil selengkapnya dapat dilihat pada tabel 2 .

Tabel 2. Cadangan Premi untuk Benefit yang Dibayarkan pada Akhir Tahun

\begin{tabular}{|c|c|}
\hline $\begin{array}{c}\text { Jangka waktu } \\
\text { pertanggungan (n) }\end{array}$ & $\begin{array}{c}\text { Nilai Cadangan Premi untuk } \\
\text { Benefit yang Dibayarkan } \\
\text { pada Akhir Tahun }\end{array}$ \\
\hline 1 & Rp. 387.679,17 \\
\hline 2 & Rp. $799.491,46$ \\
\hline 3 & Rp. $1.237 .216,22$ \\
\hline 4 & Rp. $1.702 .569,87$ \\
\hline 5 & Rp. $2.197 .297,05$ \\
\hline 6 & Rp. $2.190 .702,24$ \\
\hline 7 & Rp. $2.715 .177,68$ \\
\hline 8 & Rp. $3.272 .813,90$ \\
\hline 9 & Rp. $3.865 .941,21$ \\
\hline 10 & Rp. $4.497 .157,93$ \\
\hline 11 & Rp. $5.169 .223,76$ \\
\hline 12 & Rp. $4.820 .282,28$ \\
\hline 13 & Rp. $5.551 .476,85$ \\
\hline 14 & Rp. $6.256 .607,58$ \\
\hline 15 & Rp. $5.452 .632,97$ \\
\hline 16 & Rp. 6.198.802,74 \\
\hline 17 & Rp. $7.000 .000,00$ \\
\hline
\end{tabular}

Perbandingan Harga Tunai dengan Cadangan Premi

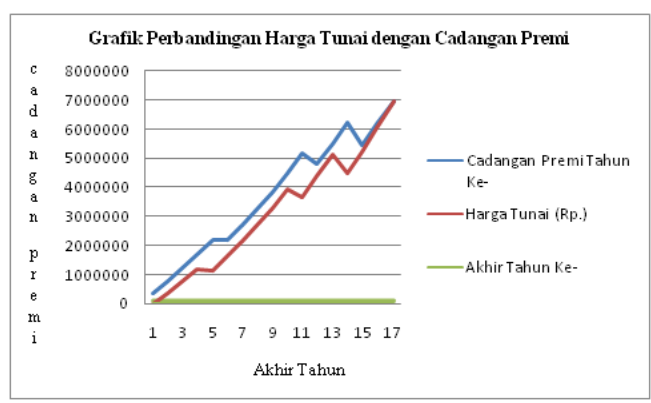

Gambar 1. Perbandingan Harga Tunai dengan Cadangan Premi

Selanjutnya, berdasarkan persamaan (2) dihitung nilai tunai manfaat yang dibayarkan pada saat pihak tertanggung meninggal dunia yang dinotasikan dengan $\bar{A}_{x: \bar{n} \mid}$ dikalikan dengan $(1+i)^{\frac{1}{2}}$ dapat ditulis sebagai berikut:

$$
\begin{aligned}
& \vec{A}_{x: \bar{n} \mid}^{p}=\frac{\left(\left(M_{x}-M_{x+n}\right)(1+i)^{\frac{1}{2}}+D_{x+n}\right)}{D_{x}} \\
& \bar{A}_{40: \overline{171}}^{p}=\frac{\left(\left(M_{40}-M_{40+17}\right)(1+0,065)^{\frac{1}{2}}+D_{40+17}\right)}{D_{40}}
\end{aligned}
$$




$$
\begin{aligned}
& =\frac{\left((1.072,06-758,36)(1+0,065)^{\frac{1}{2}}+2.459,11\right)}{7.800,49} \\
& =0,356752493
\end{aligned}
$$

Sebelum menghitung nilai premi tahunan, terlebih dahulu dihitung nilai tunai manfaat dana kelangsungan belajar dengan benefit yang dibayarkan pada saat meninggal, diperoleh:

$$
\begin{aligned}
\vec{A}_{40: 17\rceil}^{p}= & 5.000 .000 \frac{\left(\left(M_{40}-M_{40+17}\right)(1+0,065)^{\frac{1}{2}}+D_{40+17}\right)}{D_{40}} \\
& +500.000 \cdot v^{5}+1.000 .000 \cdot v^{11}+1.500 .000 \cdot v^{14} \\
& +2.000 .000 \cdot v^{17} \\
= & 3.955 .690,52
\end{aligned}
$$

Selanjutnya, dilakukan perhitungan untuk premi tahunan bersih asuransi pendidikan berdasarkan persamaan (5) dan nilai anuitas hidup yang sudah diperoleh sebelumnya, sehingga:

$$
\begin{aligned}
P & =\frac{\bar{A}_{40: 17 \mid}^{p}}{\ddot{a}_{40: 17 \mid}} \\
& =\frac{3.955 \cdot 690,52}{10,56044043} \\
& =374.576,28
\end{aligned}
$$

Berdasarkan persamaan (6) dan nilai tunai manfaat dana kelangsungan belajar, dihitung nilai premi bulanan asuransi pendidikan dengan benefit yang dibayarkan pada saat pihak tertanggung meninggal dunia:

$$
\begin{aligned}
P^{(12)} \cdot \ddot{a}_{40: \overline{17 \mid}}^{(12)} & =\bar{A}_{40: 17 \mid}^{p} \\
P^{(12)} & =\frac{3.955 \cdot 690,52}{(12)(10,24659712)} \\
& =32 \cdot 170,76
\end{aligned}
$$

Berdasarkan persamaan (18) dan nilai dana kelangsungan belajar $A P_{t}$ yang sudah diperoleh sebelumnya, maka dapat ditentukan besar nilai cadangan premi dengan benefit yang dibayarkan pada saat pihak tertanggung meninggal dunia:

Cadangan Premi Tahun Ke-1:

$$
\begin{aligned}
{ }_{1} \bar{V}_{40}= & \frac{1}{l_{x+t}}\left[5 \cdot 10^{6}(1+i)^{\frac{1}{2}}\left(\frac{M_{41}+M_{57}}{D_{41}}\right)+5.10^{6}\right. \\
& \left.\times l_{57} \cdot v^{16}-P\left(\frac{N_{41}+N_{57}}{D_{41}}\right)\right]+A P_{1}
\end{aligned}
$$

berlaku juga untuk seterusnya. Hasil selengkapnya dapat dilihat pada tabel 3 .
Tabel 3. Cadangan Premi untuk Benefit yang Dibayarkan pada Saat Meninggal Dunia

\begin{tabular}{|c|c|}
\hline $\begin{array}{c}\text { Jangka waktu } \\
\text { pertanggungan (n) }\end{array}$ & $\begin{array}{c}\text { Nilai Cadangan Premi untuk } \\
\text { Benefit yang Dibayarkan } \\
\text { pada Saat Meninggal Dunia }\end{array}$ \\
\hline 1 & Rp. 388.083,75 \\
\hline 2 & Rp. $800.292,50$ \\
\hline 3 & Rp. $1.238 .406,83$ \\
\hline 4 & Rp. $1.704 .139,70$ \\
\hline 5 & Rp. 2.199.228,87 \\
\hline 6 & Rp. 2.192.968,38 \\
\hline 7 & Rp. 2.717.739,31 \\
\hline 8 & Rp. 3.275.620,30 \\
\hline 9 & Rp. 3.868.928,90 \\
\hline 10 & Rp. 4.500.249,72 \\
\hline 11 & Rp. 5.172.321,36 \\
\hline 12 & Rp. 4.823.264,58 \\
\hline 13 & Rp. 5.517.487,72 \\
\hline 14 & Rp. 6.258.923,51 \\
\hline 15 & Rp. 5.454.368,54 \\
\hline 16 & Rp. 6.199.772,06 \\
\hline 17 & Rp. 7.000.000,00 \\
\hline
\end{tabular}

Penentuan cadangan premi untuk asuransi pendidikan dengan perhitungan prospektif menggunakan orientasi waktu yang akan datang. Nilai cadangan dilihat berdasarkan usia awal pihak tertanggung saat memulai asuransi dan memperhatikan manfaat-manfaat yang harus dibayarkan oleh perusahaan kepada pihak tertanggung, dalam kasus ini adalah dana kelangsungan belajar. Dana kelangsungan belajar yang dikembalikan oleh pihak perusahaan asuransi sebesar Rp.500.000 pada tahun ke-5, Rp.1.000.000 pada tahun ke-11, Rp.1.500.000 pada tahun ke-14 dan Rp.2.000.000 pada tahun ke-17 yang sekaligus dibayarkan dengan uang pertanggungan sebesar Rp.5.000.000.

\section{SIMPULAN DAN SARAN}

\section{A. Simpuan Penelitian}

Penelitian ini menunjukkan bahwa formula menggunakan perhitungan prospektif untuk menentukan besar nilai cadangan premi dengan benefit yang dibayarkan pada akhir tahun dirumuskan dengan:

$$
{ }_{t} V_{x}=\frac{1}{l_{x+t}}\left[5.10^{6}\left(\frac{M_{x+t}-M_{x+n}}{D_{x+t}}\right)+l_{x+n} \cdot v^{n-t}\right]
$$




$$
-P\left(\frac{N_{x+t}-N_{x+n}}{D_{x+t}}\right)+A P_{t}
$$

dan formula menggunakan perhitungan prospektif untuk menentukan besar nilai cadangan premi dengan benefit yang dibayarkan pada saat pihak tertanggung meninggal dunia dirumuskan dengan:

$$
\begin{aligned}
{ }_{t} \bar{V}_{x}= & \frac{1}{l_{x+t}}\left[5.10^{6}(1+i)^{\frac{1}{2}}\left(\frac{M_{x+t}+M_{x+n}}{D_{x+t}}\right)\right. \\
& +5.10^{6} \times l_{x+n} \cdot v^{n-t} \\
& -P\left(\frac{N_{x+t}+N_{x+n}}{D_{x+t}}\right)+A P_{t}
\end{aligned}
$$

Untuk hasil analisis penentuan cadangan premi menggunakan perhitungan prospektif untuk benefit yang dibayarkan pada akhir tahun ataupun nilai cadangan premi untuk benefit yang dibayarkan pada saat pihak tertanggung meninggal dunia sama dengan nilai harga tunai yang ditetapkan oleh pihak perusahaan pada akhir tahun ke-17.

\section{B. Saran}

Pada penelitian ini penulis menentukan besar nilai cadangan premi untuk asuransi pendidikan dengan asumsi bunga konstan, disarankan untuk penelitian selanjutnya menggunakan jenis asuransi jiwa yang lain dan menggunakan tingkat suku bunga yang tidak konstan.

\section{DAFTAR PUSTAKA}

Destriani, Satyahadewi, N. \& Mara, M.N., 2014. Penentuan Prospektif pada Asuransi Jiwa Seumur Hidup Menggunakan Metode New Jersey. Buletin Ilmiah Mat.Stat dan Terapannya (BIMASTER), No.3, Pp.7-12.

Dickson, D.C.M., Hardy, M.R \& Waters, H.R., 2009. Actuarial Mathematics for Life Contingent Risk. New York: Cambridge UniversityPress.

http://bookzz.org./md5/C4ADC30B53F17D6 B9B989D728A56DB11. Diakses 02 Februari 2017.

Futami, T. 1993. Matematika Asuransi Jiwa Bagian I. Herliyanto G, penerjemah. Tokyo: Oriental Life Insurance Cultural Development Center. Terjemahan dari: Seime Hoken Sugaku Gekan ("92 Revision).

Prodjodikoro, W. 1987. Hukum Asuransi di Indonesia, Jakarta: Intermasa.

Sembiring, R. 1986. Buku Materi Pokok Asuransi I Modul 1-5. Jakarta: Karunika.

Sukirno, S. 1994. Pengantar Teori Makro. Jakarta: Raja grafindo. 